S. VAN PETEGEM
D. SEGERS
D,
V. PELOSIN
3
J. KURIPLACH

\section{Characterization of defects in a martensitic CuAINi shape-memory alloy}

\author{
${ }^{1}$ NUM/ASQ, Paul Scherrer Institute, Villigen PSI 5232, Switzerland \\ ${ }^{2}$ Department of Subatomic and Radiation Physics, Ghent University, Proeftuinstraat 86, \\ 9000 Ghent, Belgium \\ ${ }^{3}$ Laboratoire de Mécanique et de Physique des Matériaux, ENSMA, CNRS, 86961 Futuroscope, France \\ ${ }^{4}$ Department of Low Temperature Physics, Charles University, Prague, Czech Republic
}

\section{Received: 3 March 2004/Accepted: 13 May 2004}

Published online: 9 July 2004 • C Springer-Verlag 2004

ABSTRACT A water-quenched martensitic CuAlNi shapememory alloy was investigated by a combination of coincidence Doppler broadening and positron-lifetime spectroscopy, supported by positron-lifetime calculations. We find a high defect concentration in the as-quenched samples. The positronlifetime calculations suggest that the defects are not only single vacancies but also vacancies associated with dislocations and stacking faults. Annealing in the martensitic phase has no significant influence on the vacancy concentration but results in a different chemical environment around the vacancies. After aging in the austenitic phase the vacancy concentration decreases significantly.

PACS 61.72.Ji; 78.70.Bj

\section{$1 \quad$ Introduction}

Nowadays, shape-memory alloys are extensively studied because of their high damping capacity in the martensitic phase. $\mathrm{Cu}$-based alloys are particularly interesting because they can be used at high temperatures. At high temperatures these alloys are in a stable bcc disordered beta phase. After quenching a martensitic structure is obtained. It is well known that a relatively high concentration of quenched-in vacancies is created.

The role of quenched-in vacancies in $\mathrm{Cu}-\mathrm{Al}-\mathrm{Ni}$ has been studied in the past by e.g. resistivity measurements [1-4]. Vacancies are believed to play an important role in the reversible martensite to austenite transformation and are responsible for the martensite stabilization effect observed in this type of alloy.

In this paper we report the study of $\mathrm{Cu}-13.2 \mathrm{wt} \% \mathrm{Al}-$ $3.1 \mathrm{wt} \% \mathrm{Ni}$. This material has been studied before by Covarel et al. [3] using internal friction and electrical resistivity measurements. They have shown that after annealing in the martensitic phase no significant change in the vacancy concentration could be observed. But, on the other hand, internal friction measurements clearly show a structural change in the specimens. The aim of this work is to identify the nature of

E-mail: steven.vanpetegem@psi.ch the defects in water-quenched $\mathrm{CuAlNi}$ alloys using positronlifetime spectroscopy and coincidence Doppler-broadening spectroscopy.

Positron annihilation lifetime spectroscopy has proven to be a very sensitive probe for various defects in solids [5]. Positrons have a positive charge and are therefore attracted to vacancies, dislocations and other free-volume defects. Once a positron is trapped inside such a free volume, the lifetime of the positron can be directly related to the size of that free volume. In this way it is possible to detect defects as small as vacancies at concentrations as low as $10^{-7}$ at $^{-1}$.

Measuring Doppler broadening of annihilation radiation allows the identification of the chemical surroundings of the defects [6]. The photons that are created during the electronpositron annihilation are detected by germanium detectors. The shape of the resulting photo-peak reflects the momentum distribution of the original electron-positron pairs. This distribution in its high-momentum part is unique for each chemical species (see [6] for details).

For previous positron-annihilation studies on copperbased martensites we refer the reader to [1, 2, 7-16] and more specifically to $[12-14,16]$ for the study of CuAlNi alloys. Most of these studies focussed on the defect behavior during the martensitic transformation by investigating the $S$ parameter and the mean positron lifetime as a function of aging temperature. In this paper we focus on the detailed characterization of such defects regarding their size, concentration and chemical environment.

\section{$2 \quad$ Experimental procedures}

2.1 Sample preparation

All the specimens used for this study have the same composition: $\mathrm{Cu}-13.2 \mathrm{wt} \% \mathrm{Al}-3.1 \mathrm{wt} \% \mathrm{Ni}\left(\mathrm{Cu}_{70.9} \mathrm{Al}_{26.3} \mathrm{Ni}_{2.8}\right)$. They were homogenized at $1400{ }^{\circ} \mathrm{C}$ for $10 \mathrm{~min}$ before quenching in water at room temperature. This results in an ordered martensitic $\beta_{1}^{\prime}$ structure (18R). Differential scanning calorimetry measurements indicate that the temperature $\left(M_{\mathrm{S}}\right)$ when upon cooling the martensite starts to appear is about $150^{\circ} \mathrm{C}$. The specimens were annealed at $97^{\circ} \mathrm{C}$ and $200{ }^{\circ} \mathrm{C}$, i.e. at temperatures well below and above $M_{\mathrm{s}}$. Resistivity measurements of these samples have shown that the vacancy concentration is not influenced by aging in the martensitic phase [3]. After 
aging in the austenitic phase the vacancy concentration decreases.

\section{2}

\section{Positron-annihilation spectroscopy}

The positron-lifetime measurements were performed with a conventional fast-fast lifetime spectrometer (see e.g. [5]) with a resolution (FWHM) of about $220 \mathrm{ps}$ using the sandwich arrangement. The positron source (about $0.4 \mathrm{MBq}$ ) was made by evaporating ${ }^{22} \mathrm{NaCl}$ onto a standard kapton foil (7- $\mu \mathrm{m}$ thickness), which was then sealed with another foil. The spectra all contained more than $5 \times 10^{6}$ counts and were analyzed using the multi-component program LT developed by Kansy [17]. The vacancy concentration is estimated using the simple trapping model (see e.g. [5]). In this model the defect concentration $\left(C_{\mathrm{d}}\right)$ can be calculated using the following equation:

$C_{\mathrm{d}}=\frac{I_{2}}{\mu_{\mathrm{d}}}\left(\frac{1}{\tau_{1}}-\frac{1}{\tau_{2}}\right)$,

with $I_{2}$ the intensity of the defect component, and $\tau_{1}$ and $\tau_{2}$ positron lifetimes of, respectively, the free and the trapped positrons, whereas $\mu_{\mathrm{d}}$ is the positron-trapping coefficient for the defects. This quantity is material dependent. It is a measure of the trapping efficiency of the defects in that material. As $\mu_{\mathrm{d}}$ is not known for our system, we will use the positrontrapping coefficient for vacancies in $\mathrm{B} 2 \mathrm{FeAl}\left(1.6 \times 10^{15} \mathrm{~s}^{-1}\right)$ as a first approximation [18].

The coincidence Doppler-broadening measurements were performed with the two-dimensional Doppler spectrometer at Ghent University. A full description of this setup and the data analysis is given in [19]. All spectra contained more than $30 \times 10^{6}$ counts.

The positron-lifetime measurements are supported by positron-lifetime calculations performed on perfect and defect lattices using the atomic superposition (ATSUP) method developed by Puska and Nieminen [20-22]. This method has proven to be very reliable to predict positron lifetimes in small defect structures in metallic systems. The calculations are performed within the local density approximation. We used the

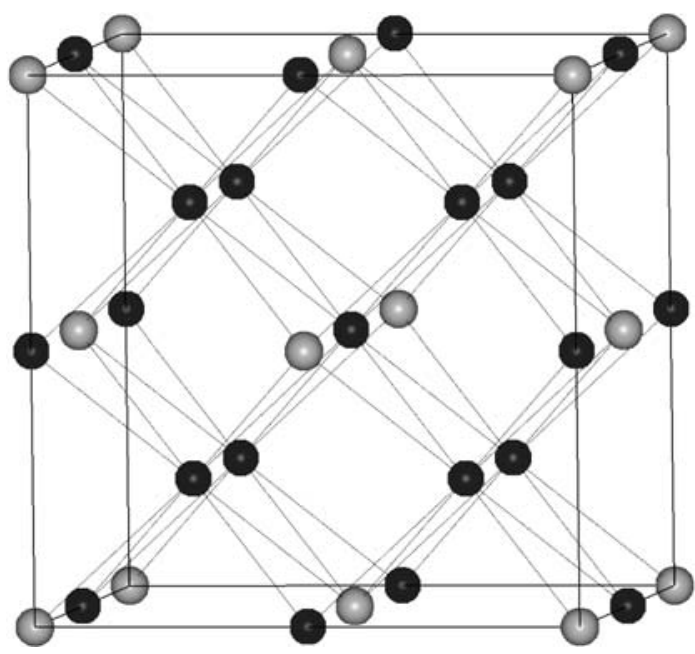

FIGURE 1 The unit cell of $\mathrm{Cu}_{3} \mathrm{Al}$ with the $\mathrm{DO}_{3}$ structure
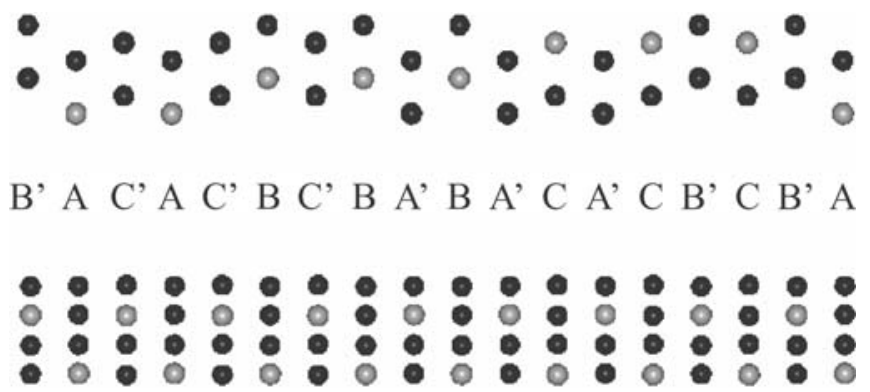

FIGURE 2 The projection of the unit cell of the martensitic $\beta_{1}^{\prime}$ phase in two directions. The symbols A, B, ... denote the six types of close-packed stacking planes (data taken from [24])

parameterization of the enhancement factor and correlation potential as proposed by Boroński and Nieminen [23].

For the martensitic $\beta_{1}^{\prime}$ phase the calculations were performed on a cell with the atomic composition $\mathrm{Cu}_{51} \mathrm{Al}_{19} \mathrm{Ni}_{2}$, which very closely corresponds to the composition of our $\mathrm{Cu}-$ $13.2 \mathrm{wt} \% \mathrm{Al}-3.1 \mathrm{wt} \% \mathrm{Ni}$ samples, and on $\mathrm{Cu}_{3} \mathrm{Al}$ with the $\mathrm{DO}_{3}$ structure, which is the parent phase of the $\beta_{1}^{\prime}$ phase (see e.g. [24]). Both structures are shown in Figs. 1 and 2. For the calculation of the defect lifetimes in the $\mathrm{DO}_{3}$ and the $\beta_{1}^{\prime}$ structures we have used supercells containing, respectively, 128 and 1296 atoms.

3

3.1

Results

\section{Positron-lifetime calculations}

Table 1 shows the results of calculations of the elementary systems $\mathrm{Cu}, \mathrm{Al}$ and $\mathrm{Ni}$. The calculated bulk positron lifetime of $\mathrm{Al}$ is well reproduced whereas for the transitionmetal materials the lifetimes are somewhat too low. This has been reported before in the literature and is due to an overestimation of the contribution of the $3 d$ electrons. The positron lifetime in vacancies in $\mathrm{Cu}$ and $\mathrm{Ni}$ is underestimated by about $10 \mathrm{ps}$ for the same reason. Calculations using the generalized gradient approximation give better results for transition-metal materials, but seriously underestimate the positron lifetime in Al $[25,26]$. The latter is due to an overestimation of the enhancement of the low-momentum electrons [27].

Now we proceed with the martensitic structures. First we discuss the positron lifetime of the defect-free bulk structures. The bulk positron lifetime of both the $\mathrm{DO}_{3}$ and the $\beta_{1}^{\prime}$ structures is $117 \mathrm{ps}$. The additional $\mathrm{Al}$ and $\mathrm{Ni}$ atoms in the $\beta_{1}^{\prime}$ structure compared to the $\mathrm{Cu}_{3} \mathrm{Al}$ structure apparently have no significant effect. The calculations were performed with the

\begin{tabular}{llllllr}
\hline & \multicolumn{2}{c}{$\mathrm{Cu}(\mathrm{ps})$} & \multicolumn{2}{c}{$\mathrm{Al}(\mathrm{ps})$} & \multicolumn{2}{c}{$\mathrm{Ni}(\mathrm{ps})$} \\
& $\exp$ & calc & $\exp$ & calc & exp & calc \\
& & & & & & \\
\hline Bulk & 114 & 109 & 166 & 168 & 105 & 97 \\
Vacancy & 180 & 168 & 238 & 243 & 175 & 166 \\
\hline
\end{tabular}

TABLE 1 Overview of experimental (exp) and calculated (calc) positron lifetimes in $\mathrm{Cu}, \mathrm{Al}$ and $\mathrm{Ni}$. The experimental vacancy positron lifetimes for $\mathrm{Cu}$ and $\mathrm{Al}$ were, respectively, taken from [28] and [29]. The other values were measured at Ghent University 
$\mathrm{Ni}$ atoms at several different positions in the lattice, but this turned out to have no influence on the bulk lifetime. This could be expected because in these bulk structures the positron wavefunction is delocalized, which makes the positron lifetime rather insensitive to the local structure. A small variation of the $\mathrm{Al}$ content $\left(\mathrm{Cu}_{48} \mathrm{Al}_{22} \mathrm{Ni}_{2}-\mathrm{Cu}_{54} \mathrm{Al}_{16} \mathrm{Ni}_{2}\right)$ in both structures (to mimic local differences in the composition) resulted in lifetime changes smaller than $1 \mathrm{ps}$ (no change of the lattice constant was considered here).

To calculate the positron lifetime in vacancies in $\mathrm{D}_{3}$ $\mathrm{Cu}_{3} \mathrm{Al}$, we have to take into account that there exist two possible crystallographically non-equivalent positions for the $\mathrm{Cu}$ vacancy and one for the $\mathrm{Al}$ vacancy. They are characterized by the composition of the eight nearest neighbors. The results are shown in Table 2. We did not take lattice relaxations around the vacancies into account. The lifetimes of $\mathrm{Cu}$ and $\mathrm{Al}$ vacancies differ by only a few ps, which makes it impossible to distinguish between them in positron-lifetime experiments. In the $\beta_{1}^{\prime}$ phase there exist several possible vacancy sites. In a first step we have calculated the positron lifetimes for all the possible vacancy configurations for the $\beta_{1}^{\prime}$ phase when neglecting the $\mathrm{Ni}$ content (i.e. $\mathrm{Cu}_{54} \mathrm{Al}_{18}=\mathrm{Cu}_{3} \mathrm{Al}$ ). The result is shown in Fig. 3. The Al vacancies have on average a slightly larger lifetime than the $\mathrm{Cu}$ vacancies, but again here the differences are very small. In a next step extra $\mathrm{Al}$ and $\mathrm{Ni}$ atoms are added close to the vacancy sites. This gives only secondorder corrections (smaller than $1 \mathrm{ps}$ ) for the vacancy lifetimes. These results show that positron-lifetime spectroscopy is not suitable to distinguish different chemical surroundings of vacancies in the CuAlNi martensitic structure.

As a last step we calculate the positron lifetime of divacancies. The presence of di-vacancies in quenched CuAlNi

\begin{tabular}{lcc}
\hline Vacancy type & Lifetime (ps) & Nearest neighbors \\
\hline $\mathrm{Cu}_{\mathrm{v}}$ & 185 & $8 \mathrm{Cu}$ \\
$\mathrm{Cu}_{\mathrm{v}}$ & 182 & $4 \mathrm{Cu}-4 \mathrm{Al}$ \\
$\mathrm{Al}_{\mathrm{v}}$ & 185 & $8 \mathrm{Cu}$ \\
\hline
\end{tabular}

TABLE 2 Overview of calculated positron lifetimes of vacancies in $\mathrm{Cu}_{3} \mathrm{Al}$ $\left(\mathrm{D}_{3}\right.$ phase $)$

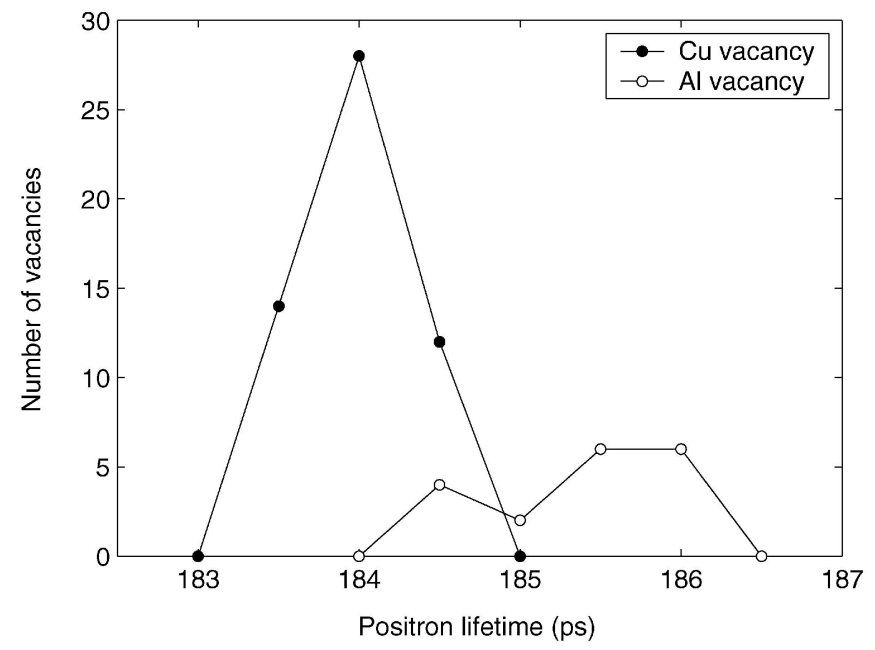

FIGURE 3 Histogram of calculated positron lifetimes in all 72 vacancy configurations in $\mathrm{Cu}_{3} \mathrm{Al}$ with the $\beta_{1}^{\prime}$ structure
TABLE 3 Overview of calculated positron lifetimes in di-vacancies in $\mathrm{Cu}_{3} \mathrm{Al}\left(\mathrm{D}_{3}\right.$ phase)

\begin{tabular}{lcc}
\hline Di-vacancy type & Lifetime (ps) & Direction \\
\hline $\mathrm{Cu}-\mathrm{Al}$ & 209 & {$[111]$} \\
$\mathrm{Cu}-\mathrm{Cu}$ & 210 & {$[111]$} \\
$\mathrm{Cu}-\mathrm{Al}$ & 195 & {$[100]$} \\
$\mathrm{Cu}-\mathrm{Cu}$ & 195 & {$[100]$} \\
\hline
\end{tabular}

has been reported in [16]. In the $\mathrm{DO}_{3} \mathrm{Cu}_{3} \mathrm{Al}$ structure two types of di-vacancies can be produced by taking away the atoms in, respectively, the [111] and the [100] directions. The results are shown in Table 3. The lifetime of the di-vacancies in the [111] direction is about 25 ps larger than the lifetime of mono-vacancies. The di-vacancies in the [100] direction are formed by second-nearest neighbors and therefore have a positron lifetime that is only $10 \mathrm{ps}$ larger than the monovacancy lifetime. Di-vacancies formed by atoms that are not first- or second-nearest neighbors (e.g. in the [110] direction) exhibit lifetimes similar to the mono-vacancy lifetime. In the case of the $\beta_{1}^{\prime}$ structure the situation is somewhat different. The lifetimes of di-vacancies formed by the nearest neighbors vary between $207 \mathrm{ps}$ and $208 \mathrm{ps}$, similarly to di-vacancies in the $\mathrm{D}_{3}$ structure. But all other di-vacancies have the same lifetime as the mono-vacancies, so no intermediate di-vacancy lifetimes were found.

\subsection{Positron-lifetime measurements}

An overview of the positron-lifetime results is given in Table 4 . The samples 1, 2 and 3 exhibit only one positron lifetime, which is clearly larger than the expected bulk lifetime. This is an indication for saturation trapping; the concentration of defects is so high that all the positrons are trapped. This means that it is not possible to retrieve exact information about the defect concentration in these samples.

The defect lifetimes of all samples are equal to or somewhat lower than the calculated positron lifetime in vacancies. This agreement between theory and experiment has also been reported for other $\mathrm{D}_{3}$ structures (see e.g. [11]). It would therefore be tempting to ascribe this defect component to single vacancies. But we have to take into account that for $\mathrm{Cu}$ the calculated lifetime is underestimated with respect to the experimental lifetime. The positron lifetime of a vacancy in $\mathrm{Cu}$ is underestimated by more than $10 \mathrm{ps}$. Therefore, we would expect that vacancies have an experimental positron lifetime of at least $190 \mathrm{ps}$. A possible explanation could be the fact that the specimens contain other defects. Indeed, transmis-

\begin{tabular}{rcrcccc}
\hline$N$ & $\begin{array}{c}\text { Annealing } \\
T\left({ }^{\circ} \mathrm{C}\right)\end{array}$ & Time (h) & $\begin{array}{c}\tau_{1} \\
(\mathrm{ps})\end{array}$ & $\begin{array}{c}\tau_{2} \\
(\mathrm{ps})\end{array}$ & $\begin{array}{c}I_{1} \\
(\%)\end{array}$ & $\begin{array}{c}I_{2} \\
(\%)\end{array}$ \\
\hline 1 & 25 & - & - & 182 & - & 100 \\
2 & 97 & 1 & - & 180 & - & 100 \\
3 & 97 & 24 & - & 180 & - & 100 \\
4 & 200 & 1 & 106 & 179 & 50 & 50 \\
5 & 200 & 197 & 103 & 180 & 50 & 50 \\
\hline
\end{tabular}

TABLE 4 Overview of the positron lifetimes in CuAlNi quenched from $860^{\circ} \mathrm{C}$ as a function of annealing temperature and time. $\tau$ and $I$ represent, respectively, the positron lifetime and the relative intensity 
sion electron microscopy observations showed the presence of numerous stacking faults and disoriented variants. According to positron-lifetime calculations performed by Häkkinen et al. the lifetime of $\mathrm{Cu}$ vacancies related to (edge) dislocations or stacking-fault regions should be, respectively, $10 \%$ and $4 \%$ lower than the vacancy lifetime [30]. So, possibly at least a part of the positrons is trapped in vacancies associated with other defects such as dislocations and/or stacking faults. There is no evidence for the presence of a significant amount of di-vacancies in our specimens.

Samples 1, 2 and 3 exhibit saturation trapping, so (1) cannot be used to calculate the vacancy concentration. We can only state that the vacancy concentration is higher than $10^{-4} \mathrm{at}^{-1}$. A sample quenched from $760^{\circ} \mathrm{C}$ revealed the same results. The positron lifetimes of samples 1,2 and 3 are the same within the error limits. The structural change that is observed with internal friction apparently has no influence on the size of the defects that are detected with positrons. Resistivity measurements have also shown that the vacancy concentration does not change during $40 \mathrm{~h}$ annealing at temperatures below $M_{\mathrm{S}}$ [3]. This has also been observed by Kong et al. for $\mathrm{Cu}-13.2 \mathrm{wt} \% \mathrm{Al}-3.1 \mathrm{wt} \% \mathrm{Ni}$ quenched from $800^{\circ} \mathrm{C}[16]$. They investigated the variation of the $S$ parameter (see later) as a function of aging time at different aging temperatures. In contrast to $\mathrm{Cu}-\mathrm{Zn}-\mathrm{Al}$, no change in the $S$ parameter was found for aging temperatures below the temperature of the beginning of the reverse martensitic transformation. This effect was ascribed to the fact that $\mathrm{Ni}$ is primarily located at the $\mathrm{Cu}$ sites with $\mathrm{Al}$ nearest neighbors [31]. This causes a strong bonding between $\mathrm{Ni}$ and $\mathrm{Al}$, which retards diffusion in the martensitic state.

After annealing at $200^{\circ} \mathrm{C}$ a second lower lifetime appears. This is an indication for an irreversible decrease of the vacancy concentration. This is in agreement with resistivity measurements [3]. The vacancy concentration can be estimated at about $1.2 \times 10^{-6}$. The results for short and long annealing are the same. Apparently the remaining vacancies are rather stable at this temperature. This has also been observed by Kong et al. [16].

\subsection{Doppler-broadening measurements}

Doppler spectra are often analyzed in terms of the $S$ and $W$ parameters. They are defined as the relative contributions of, respectively, the central part and the outer part of the annihilation peak compared to the whole peak (area) [32]. The $S$ parameter is mainly sensitive to changes in the lowmomentum part of the annihilation peak, i.e. to changes in the contribution of conduction and valence electrons. The $W$ parameter reflects the contribution of the high-momentum electrons to the annihilation peak and is therefore a measure of the contribution of the core electrons. Compared to conventional Doppler measurements, coincidence Doppler measurements have the advantage of a very large peak-to-background ratio. Therefore, no background corrections are necessary, which makes the $S$ and $W$ parameters of different samples more reliable compared to those obtained from single Doppler spectra.

The Doppler profiles of the CuAlNi samples were recorded together with the profiles for $\mathrm{Cu}, \mathrm{Al}$ and $\mathrm{Ni}$ for comparison.
The best way to represent the $S$ and $W$ data is in a $S-W$ plot as shown in Fig. 4. $\mathrm{Cu}, \mathrm{Al}$ and Ni clearly have wellseparated $S-W$ points due to their different electronic and crystallographic structures. This makes it possible to distinguish between them in a $S-W$ plot. Upon trapping, the overlap of the positron wavefunction with the wavefunctions of the core electrons decreases drastically. This leads to a decrease of the $W$ parameter and an increase of the $S$ parameter. This is evidenced in Fig. 4, where the $S-W$ points for defect-rich (deformed) $\mathrm{Ni}$ and $\mathrm{Cu}$ are shown. It can be shown that for a given material a change in the defect concentration results in $S-W$ points that lie on a straight line in a $S-W$ plot [5]. This can be seen in the case of our CuAlNi samples. When we extrapolate this line, we end up with defect-free copper. This could be an indication that the vacancies are mainly surrounded by $\mathrm{Cu}$ atoms. Furthermore, the $S-W$ point of deformed $\mathrm{Cu}$ is located very close to the $S-W$ points of CuAlNi.

The $S-W$ point after annealing at $97^{\circ} \mathrm{C}$ is different than before annealing. At first sight this is an indication that the defect concentration has decreased. But the positron-lifetime and resistivity measurements indicate no change in defect concentration. So, we have to look for other possible reasons for this behavior. As we can see in Fig. 4, the $S-W$ point for $\mathrm{Al}$ is very close to the straight line connecting $\mathrm{CuAlNi}$ and $\mathrm{Cu}$. This is an indication that by using a $S-W$ plot it would be very difficult to distinguish between changes from an $\mathrm{Al}$ to a $\mathrm{Cu}$ environment and changes in the defect concentration.

After annealing in the austenitic phase the defect concentration decreased significantly, leading to a lower $S$ and a higher $W$ value. There is no sign of preferential trapping near $\mathrm{Ni}$ atoms, as in that case the $S-W$ point would deviate from the straight line towards the Ni point.

The next step is to compare the Doppler profiles themselves. These profiles typically span about five orders of magnitude. To highlight the differences among these profiles, we have made ratio curves with respect to the profile of graphite. The area of each spectrum was first normalized to unity before making the ratio curves. The results are shown in Fig. 5. The ratio curve of sample 3 is the same as for sample 2, but for clarity of the figure it is not shown. All ratio curves, except for the one of $\mathrm{Al}$, are dominated by a large peak between 15 and

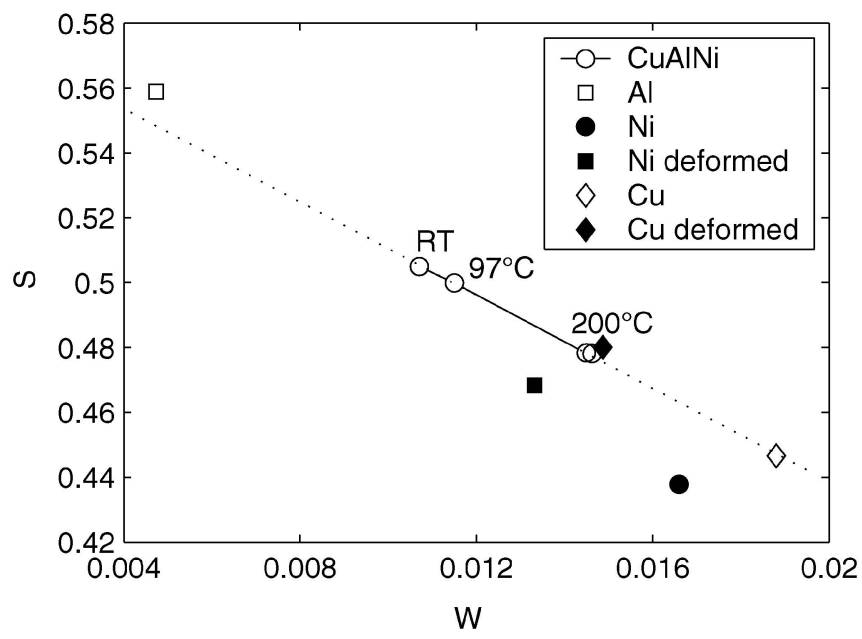

FIGURE $4 \quad S-W$ plot of CuAlNi, $\mathrm{Ni}, \mathrm{Cu}$ and $\mathrm{Al}$ 


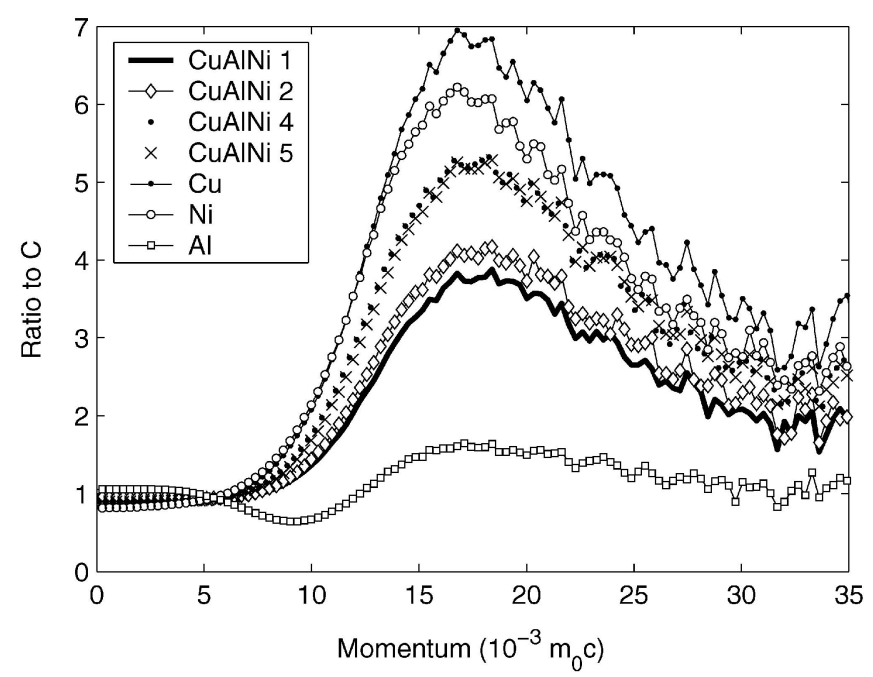

FIGURE 5 Ratio Doppler profiles of $\mathrm{CuAlNi}, \mathrm{Ni}, \mathrm{Cu}$ and $\mathrm{Al}$ with respect to graphite

$25 \times 10^{-3} m_{0} c$, which is due to the contribution of the $3 d$ electrons. Pure $\mathrm{Cu}$ and $\mathrm{Ni}$ have rather similar ratio curves, as they are adjacent in the elemental table, but the maximum of the $\mathrm{Cu}$ profile is shifted by about $2.5 \times 10^{-3} \mathrm{~m}_{0} c$ towards higher momentum compared to that of $\mathrm{Ni}$.

The maximum of the CuAlNi ratio curves is located close to that of $\mathrm{Cu}$. This is an indication that the defects are mainly surrounded by $\mathrm{Cu}$ atoms, as could be expected. Samples 1 and 2 have clearly different ratio curves, whereas they have similar positron-lifetime characteristics. Therefore, this difference can only be due to a different chemical environment. A Ni enrichment or impoverishment around the defects would result in a shift of the peak maximum, which is not the case here. The Al ratio curve is rather flat compared to that of the other samples. Therefore, a change in the $\mathrm{Al}$ contribution in the $\mathrm{CuAlNi}$ Doppler profiles could lead to a change in the height of the peak in the ratio curves, but not in a shift of the peak maxima. This hypothesis is confirmed when we subtract a fraction $f$ of the Al Doppler profile from the profile of sample 1 and renor-

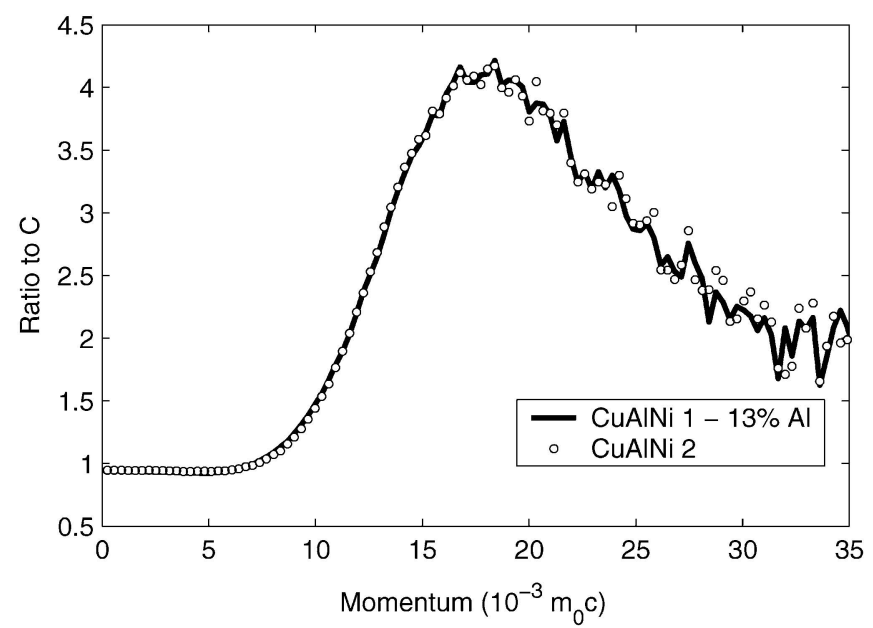

FIGURE 6 Doppler profiles of sample 1 corrected for the $\mathrm{Al}$ contribution compared to the Doppler profile of sample 2. The spectra are normalized with respect to $\mathrm{C}$ malize the resulting spectrum to unity. The ratio curve of the latter spectrum coincides perfectly with that of sample 2 for $f=13 \%$. This is evidenced in Fig. 6. It should be noted that this is independent of the Doppler profile used to normalize the spectra. The same observation was made when the ratio curves were made with $\mathrm{Al}$ and $\mathrm{Ti}$, which highlight different parts of the Doppler profiles.

So again here we can conclude that a change from a defect environment with fewer $\mathrm{Al}$ atoms can hardly be differentiated from a change in defect concentration. As the latter was not observed by both positron-lifetime and resistivity measurements, we can conclude that aging at $97^{\circ} \mathrm{C}$ induces a structural change so that the trapped positrons see a lower fraction of electrons belonging to $\mathrm{Al}$ atoms. This could indicate that after aging a larger fraction of the vacancies are located at the $\mathrm{Al}$ sites, or at the $\mathrm{Cu}$ sites with mainly $\mathrm{Cu}$ atoms as nearest neighbors.

After aging at $200^{\circ} \mathrm{C}$ the Doppler profile is much closer to that of pure $\mathrm{Cu}$. This is mainly due to the lower vacancy concentration in these samples.

\section{Conclusions}

We have studied defects in water-quenched martensitic $\mathrm{Cu}-13.2 \mathrm{wt} \% \mathrm{Al}-3.1 \mathrm{wt} \% \mathrm{Ni}$ using positron-annihilation spectroscopy. Positron annihilation lifetime spectroscopy, supported by positron-lifetime calculations, reveals a large fraction of defects $\left(>10^{-4} \mathrm{at}^{-1}\right)$ in the as-quenched samples. Positron-lifetime calculations show that one should be careful in ascribing the defect component in these kinds of materials to single vacancies. We rather believe that the defect component is a combination of single vacancies and vacancies associated with dislocations and stacking faults.

Aging at $97^{\circ} \mathrm{C}$ did not show any change in positronlifetime characteristics, contrary to what has been found for many other water-quenched $\mathrm{Cu}$-based martensitic materials. Aging at $200^{\circ} \mathrm{C}$ results in a large reduction of the vacancy concentration to $1.2 \times 10^{-6}$ at $^{-1}$. These vacancies are stable at these temperatures. Coincidence Doppler broadening measurements show that the vacancies are mainly surrounded by $\mathrm{Cu}$ atoms. During aging at $97{ }^{\circ} \mathrm{C}$ a structural change occurs, as evidenced by internal friction experiments. Doppler measurements suggest that this structural change results in a redistribution of the vacancies, leading to fewer $\mathrm{Al}$ atoms around the annihilation site. This could be an indication that after aging the vacancies are mainly located at $\mathrm{Al}$ sites, or at $\mathrm{Cu}$ sites with mainly $\mathrm{Cu}$ atoms as nearest neighbors.

ACKNOWLEDGEMENTS We thank M.J. Puska for providing us with his ATSUP code. We also acknowledge the help of N. Caenegem. This research is part of the Interuniversity Poles of Attraction Program - Belgian State, Prime Minister's Office - Federal Office for Scientific, Technical and Cultural Affairs (IUAP 5/1).

\section{REFERENCES}

1 B. Kostrubiec, J. Rasek, R. Wisniewski, H. Morawiec: Solid State Phenom. 89, 287 (2003)

2 B. Kostrubiec, J. Rasek, A. Salamon, H. Morawiec: J. Mater. Sci. 37, 369 (2002)

3 G. Covarel, V. Pelosin, A. Rivière: Scr. Mater. 46, 319 (2002) 
4 V. Pelosin, A. Rivière: J. Alloys Compd. 268, 166 (1998)

5 P. Hautojärvi, C. Corbel: in: Positron Spectroscopy of Solids, ed. by A. Dupasquier, A.P. Mills, Jr. (IOS, Amsterdam 1995) p. 491

6 P. Asoka-Kumar, M. Alatalo, V.J. Ghosh, A.C. Kruseman, B. Nielsen, K.G. Lynn: Phys. Rev. Lett. 77, 2097 (1996)

7 R. Romero, A. Somoza: Mater. Sci. Eng. A 273-275, 572 (1999)

8 A. Somoza, R. Romero, L. Mañosa, A. Planes: J. Appl. Phys. 85, 130 (1999)

9 L. Mañosa, M. Jurado, A. Gonzàlez-Comas, E. Obrado, A. Planes, J. Zarestky, C. Stassis, R. Romero, A. Somoza, M. Morin: Acta Mater. 46, 1045 (1998)

10 R. Romero, A. Somoza, M. Jurado, A. Planes, L. Mañosa: Acta Mater. 45, 2101 (1997)

11 F. Plazaola, R. Romero, A. Somoza: Nuovo Cimento 19, 695 (1997)

12 I. Hurtado, D. Segers, J. Van Humbeeck, L. Dorikens-Vanpraet, C. Dauwe: Scr. Metall. Mater. 33, 741 (1995)

13 D. Segers, I. Hurtado, L. Dorikens-Vanpraet, J. Van Humbeeck: J. Phys. IV 5, C1-163 (1995)

14 I. Hurtado, D. Segers, L. Dorikens-Vanpraet, C. Dauwe, J. Van Humbeeck: J. Phys. IV 5, C8-949 (1995)

15 W. Salgueiro, R. Romeiro, A. Somoza, M. Ahlers: Phys. Status Solidi A 138, 111 (1993)

16 Y.J. Kong, B.H. Jiang, T.Y. Hsu, B.Y. Wang, T.M. Wang: Phys. Status Solidi A 133, 269 (1992)
17 J. Kansy: J. Nucl. Instrum. Methods A 374, 235 (1996)

18 J. Wolff, A. Broska, M. Franz, B. Köhler, T. Hehenkamp: Mater. Sci. Forum 255-257, 593 (1997)

19 S. Van Petegem, B. Van Waeyenberge, D. Segers, C. Dauwe: Nucl. Instrum. Methods A 513, 622 (2003)

20 M.J. Puska, R.M. Nieminen: J. Phys. F 13, 333 (1983)

21 M.J. Puska, R.M. Nieminen: Rev. Mod. Phys. 66, 841 (1994)

22 A.P. Seitsonen, M.J. Puska, R.M. Nieminen: Phys. Rev. B 51, 14057 (1995)

23 E. Boroński, R.M. Nieminen: Phys. Rev. B 34, 3820 (1986)

24 S. Miyazaki, K. Otsuka: ISIJ Int. 29, 353 (1989)

25 B. Barbiellini, M.J. Puska, T. Torsti, R.M. Nieminen: Phys. Rev. B 51, 7341 (1995)

26 B. Barbiellini, M.J. Puska, T. Korhonen, A. Harju, T. Torsti, R.M. Nieminen: Phys. Rev. B 53, 16201 (1996)

27 P.E. Mijnarends, A.C. Kruseman, A. van Veen, H. Schut, A. Bansil: J. Phys. C: Condens. Matter 10, 10383 (1998)

28 H.E. Schaefer, W. Stuck, W. Bauer, F. Banhart: Mater. Sci. Forum 15-18, 117 (1987)

29 J.A. Ackman, G.M. Hood, R.J. Schultz: J. Phys. F: Met. Phys. 17, 1817 (1987)

30 H. Häkkinen, S. Mäkinen, M. Manninen: Phys. Rev. B 41, 12441 (1990)

31 Y. Nakata, T. Tadaki, K. Shimizu: Trans. Jpn. Inst. Met. 31, 652 (1990)

32 I.K. MacKenzie, J.A. Eady, A.A. Gingerich: Phys. Lett. A 33, 279 (1970) 